\title{
A Critical Review on Safety Management in Construction Projects
}

\author{
Patel Divya $^{1}$, Prof J.J. Bhavsar ${ }^{2}$, Dr. Jayeshkumar Pitroda ${ }^{3}$ \\ ${ }^{I}$ Final year M. Tech. Student, B. V. M. Engineering College, Vallabh Vidyanagar \\ ${ }^{2}$ Associate Professor, Civil Engineering Department, B.V.M Engineering College, Vallabh Vidyanagar \\ ${ }^{3}$ Assistant Professor, Civil Engineering Department, B.V.M Engineering College, Vallabh Vidyanagar, India \\ *Corresponding Author: Dr. Jayeshkumar Pitroda, Assistant Professor, Civil Engineering Department, \\ B.V.M Engineering College, Vallabh Vidhyanagar, Gujarat, India
}

\begin{abstract}
Safety is an imperative piece of development ventures for the workers. This paper displays an examination in development industry to enhance the security execution. The primary goal of this investigation is to recognize the basic achievement factors which are in charge of the execution of wellbeing administration in development ventures. The Indian culture and economy have endured human and budgetary misfortunes because of the poor wellbeing record in the development business. The reason for this investigation is to look at security administration in the development industry. Safety administration is basic for the coveted changes in arrangement of work and attitude. It builds up a feeling of wellbeing in work activities. It helps in obtaining essential information of perils and precautions. The consequences of the examination uncovered that there are numerous security issues in the development business, for example, absence of learning about the need of earth association for control apparatuses and absence of learning about links shield from mechanical harms. Besides, the investigation likewise proposes a few proposals for security in development industry.
\end{abstract}

Keywords: Safety, Safety Management, Safety performance, Construction, Projects

\section{INTRODUCTION}

The construction industry continues to play a major role in the development of our country and it is more labor-intensive than that in the developed areas of the globe. The construction industry seems to suffer from general inability to manage workplace health and safety to a level. In any case, it is additionally the most hazardous and risky businesses because of the novel idea of its items and the procedures involved. All development laborers must manage the absolute most dangerous and basic working conditions looked by representatives in any industry.

Security culture is being occupied with numerous associations as a way to decrease the potential for debacles, mischance and wounds. A positive wellbeing society can be a powerful apparatus for enhancing security in an association and making great climate in the workplace. Increasingly in the most recent decade, specialists have demonstrated enthusiasm for an examination on wellbeing of workers.

Security culture is being occupied with numerous associations as a way to decrease the potential for debacles, mischance and wounds. A positive wellbeing society can be a powerful apparatus for enhancing security in an association and making great climate in the workplace. Increasingly in the most recent decade, specialists have demonstrated enthusiasm for an examination on wellbeing of workers.

The purpose of this study is to utilize descriptive analysis to benchmark safety performance of construction contractors and client.

\section{Critical Literature Review}

The following are the previous research review based on safety performance of construction projects. 
Jain et al. (2007) demonstrated that in India the construction industry is the second biggest boss alongside farming though it is beside the street mischances in our country. Each site represents its own extraordinary difficulties regarding mechanical wellbeing prerequisites which must be handled by earnestness and polished methodology. Present day Modern management are useful in accomplishing these targets when utilized as a part of a taught way. (5)

Abdul Bassioni Bawazeer et al. (2007) took enthusiasm for wellbeing mindfulness among development companies. Safety management must build up and implement security polices security frameworks. They ought to regress their exercises by including all the more checking of security execution at the site and administer intermittent and irregular wellbeing examinations to guarantee the usage of wellbeing guidelines. Besides, the productivity of site security reviews by utilizing more qualified wellbeing directors with full specialist ought to be expanded. In-house normal reviews ought to be completed by skilled supervisors. (1)

Hassanein Hanna et al. (2008) in his examination introduce the consequences of a poll study that was led among a chose test of expansive size contractors. The contemplate presumed that safety programs connected by contractors working in Egypt must be more formal; prescribing nations like Egypt, where mishap protection costs are settled regardless of the temporary worker's execution, to consider the feasibility of connecting mischance expenses to the contractual worker's execution. Along these lines, contractors will follow up on enhancing safety programs, bringing about more secure exhibitions and therefore, bring down protection costs. (5)

Liang Wang et al. (2010) recognized that the viability of safety management in construction and establishment engineering venture decides the future and fortune of included enterprises. By fortifying the construction management office's safety management work, characterizing obligation of each gathering engaged with construction task, and reinforcing the supervision of government departments, safety management can be done and safety mischances in construction undertaking can be prevented. As an outcome, the generation safety in construction and establishment activities can be ensured. (11)

Charehzehi Ahankoob et al. (2012) said that, the issue of safety performance has been engaged at construction projects in both created and creating nations. Some imperative elements that make a critical bit of accidents include: safety management error, poor training programs, human element, demonstration of god, obsolete method and no reasonable monitoring approach. Therefore, they attempted to present persistent safety advancement that includes 6 stages. These means include making safety direction, distinguish peril, survey and assess chance, choose safeguard, record discoveries, and refreshing our finding in connection to the work condition. In generally, expanding safety performance and making more secure condition in construction projects require more regard for discover danger and sort of hazard that can make any damage the properties and humans. (2)

Oswald Sherrat Smith et al. (2013) asked and finished up for what valid reason do workers take a risk and work from stature with no security protection? To enable us to comprehend why there are distinctive behavioral reactions to perils in development, we should first comprehend the components that have influenced that person's decision-making. It is foreseen that fine-grained, observational examinations will yield huge understanding as to wellbeing the impact of these variables by and by, and keeping in mind the end goal to achieve this, an ethnographic member onlooker approach is to be employed. (15)

SunindijoZou et al. (2013) demonstrated that in construction projects, the management team needs to conceptualize the management of safety with a specific end goal to encourage a strong safety culture. Factor analysis of the gathered data discovered two components of conceptual expertise important to construction safety: visioning, and perusing and integration. This can be achieved by considering various project aspects which may impact the improvement of project schedule and budget; learning various contractual agreements and their impacts on the projects; understanding the stages, procedures, and activities in construction projects from initiation to completion; and improving based on a project system perspective. (19)

Kumar Vishnu et al. (2014) discovered that Jobsite safety management alludes to the cyclic procedure of planning, executing and looking into, control of work and manpower to decrease the accidents. The accidents happening in India is high compared to the remote nations with strong planning, successful implementation and continual training with centered safety management a decent safety record could be achieved comparable to international level. Therefore all the necessary factors 
which affect the jobsite safety management in constructional projects and factors affecting safety conditions of labors are formulated. (10)

Subramani Lordsonmillar et al. (2014) described that the Indian society and economy have suffered human and financial misfortunes because of the poor safety record in the construction matter. The workplaces in construction exercises are by and large more risky, than different ventures because of the utilization of substantial hardware, unsafe devices, and dangerous materials, all of which increment the potential for genuine mishaps and wounds. In this way, it is apparent that an engaged devotion inwards safety is required from construction at all levels. (20)

Nielsen Kent et al. (2014) in his International research demonstrates that internal health and safety associations (HSO) and health and safety boards (HSC) don't have the expected effect on organizations' safety performance. The investigation gives confirm that the HSO can enhance organization safety culture by concentrating on safety-related interactions. (14)

Carcano and Franco Pootet at. (2014) examined the Construction Workers' Perceptions of Safety Practices: A Case Study in Mexico. Hierarchical qualities and worker observations were among the principle factors influencing the safety atmosphere in construction locales. Albeit a few impression of workers may appear to be silly to others, these segments were a piece of their world. Worker behavior was a critical factor in working environment safety the same number of accidents were frequently caused by uncertain activities, in which mixes of human behavior were the outcome of such observations. The point of this investigation was to investigate workers' impression of safety practices in their ongoing workplace, a building site in Mexico. Worker impression of safety practices were caught utilizing an instrument in which the accompanying measurements were mulled over: Education and preparing, Work inspiration, Family and social joining, Work put mix, Safety mindfulness combination, and Accidents. The creators inferred that workers have gotten almost no training and have a constrained culture of safety mindfulness, which drove them to see that their absence of insurance was the primary driver of accidents. (8)(18)

Khan Suguna Raghunath et al. (2015) presents an investigation in construction industry to enhance the safety execution. The primary goal of this investigation is to distinguish the basic achievement factors which are in charge of the execution of safety management in construction ventures. The aftereffects of the examination uncovered that there are numerous safety issues in the construction industry, for example, absence of information about the need of earth association for control apparatuses and absence of learning about links shield from mechanical harms. Moreover, the investigation likewise proposes a few suggestions for safety in construction industry. (8)

Khan Suguna Raghunath et al. (2015) expected to furnish the respondents with fundamental data expected to better deal with the safety management in construction projects. Furthermore bringing in safety approach and measures, safety association, safety preparing, examining dangerous conditions, personal protection program, plant and equipment, safety advancement and management behavior additionally help in guaranteeing safety at construction sites. (9)

Mohd.Bibha Mahto et al. (2015) expressed that the construction industry is considered as a standout amongst the most unsafe mechanical divisions wherein the construction workers are more inclined to accidents. Occupational safety in construction industry is extremely poor in creating nations since absence of safety controls and principles, low need of safety, absence of information on safety at construction locales, absence of safety preparing, absence of safety advancement, and absence of reported and sorted out safety management systems. (12)

Kanchana Sivaprakash Joseph et al. (2015) described that construction industry has fulfilled broad development overall especially in past few decades. For a construction undertaking to be effective, safety of the structures and additionally that of the staff is of most extreme importance. The safety issues are to be viewed as ideal from the design organize till the fruition and giving over of the structure. A legitimate coordination between contractual workers, customers, and workforce is required for safe work conditions which are very much ailing in Indian construction companies. Employer can simply check enactment and draw up an appropriate wellbeing and safety design particular to business' working environment and employees. (7)

Promsorn Soponsakulrat Adulyanukosol Kaiyarit Chinda et al. (2015) in their paper look at underlying drivers of construction mishap in a non-human blunder aspect. The examinations comes about uncover three key factors affecting construction accidents, which are ergonomic design, supporting approach, and environment. It is discovered that to build up fitting safety arrangement, the 
natural and ergonomic issues, for example, ventilation, light, equipment design, and site format, ought to be considered. The explore has demonstrated that construction accidents can be caused by three key factors, which are Ergonomic Design, Environment and Supporting Policy. (16)

SaatMohd Subramaniam Shamsudin et al. (2016) inferred that safety execution has picked up acknowledgment as a field of study and has been progressively looked into nowadays. The paper recognizes and talks about the essential issues that require center before directing an examination on safety performance. Study on safety execution ought to be founded on multi-level analyses. (17)

Yiu Chan et al. (2016) depicted that the construction industry is one of the businesses considered with the most astounding mischance rates over the world in view of its high hazard and quick changing work nature. Safety administrators (safety-in-control) are thought to be one of the key staff mindful and responsible for SMS. His quality and competency were imperative to impact the execution of SMS or site safety execution. These two specific territories were additionally prescribed to be evaluated keeping in mind the end goal to better legitimize the execution of the safety management systems, together with the construction site safety performance. (21)

Jothsna Jegan et al. (2017) stated that construction works everywhere throughout the world stance genuine risk to workers and non-workers. The effects of the chronicled, sparing, mental, specialized, procedural, recurrence and the ecological issues are considered regarding how these factors are connected with the level of site safety performance. It was observed to be that the workers have gotten a constrained culture of safety awareness, which prompted primary driver of accidents. Improvement in safety culture is in this way acquired by watching and Intervening cutting edge workers. (6)

Mohammed Shamsul Bakri et al. (2017) identified that safety management is related with the arrangements, targets, techniques, strategies, parts and capacities that go for controlling peril and hazard in socio-specialized systems. The mindfulness and impression of workers toward safety, wellbeing and their workplace are essential perspective to upgrade the building construction to the better condition to the workers. Knowledge or attention to safety management framework is an imperative thought to viable safety management framework on location as high safety and wellbeing execution could enhance the association picture through less mishap, less truants of workers from work, less doctor's visit expenses, etc. (13)

Chen McCabe Hyatt et al. (2017) said that the construction industry has hit a level as far as safety performance. Safety atmosphere might be topographically touchy, in this way it is important to look at how the build of safety atmosphere is characterized and used to enhance safety execution in various regions. These discoveries feature the part of authoritative factors and in addition singular factors in influencing singular safety execution and mental well-being. Construction associations need to screen workers' safety execution as well as their mental prosperity, advancing a positive safety atmosphere. (3)

After identifying these factors, an integrated framework shown in figure 1 for assessing the factors affectingsafety performance was developed.

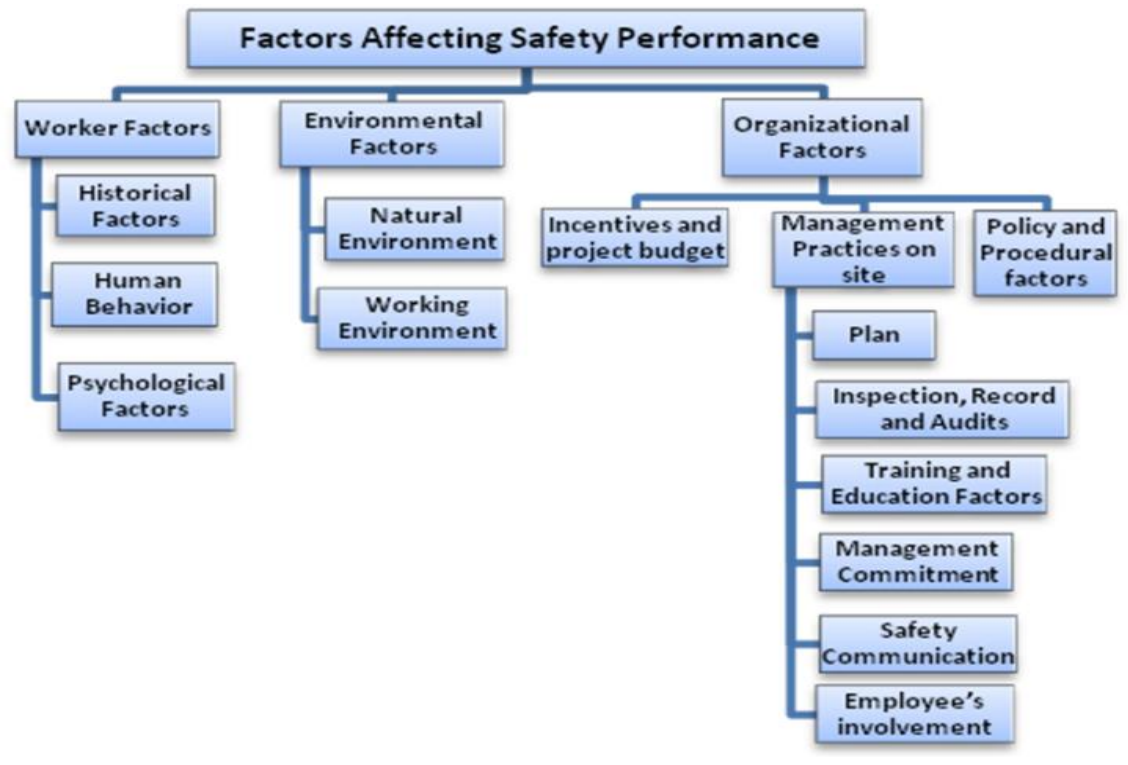

Figure1. Factors affecting safety performance 
The following table: 1 shows the representative references and factors affecting safety performance.

Table1. Representative References and factors affecting safety performance

\begin{tabular}{|c|c|}
\hline $\begin{array}{l}\text { Representative } \\
\text { References }\end{array}$ & Factors \\
\hline Jain et al. (2007) & Lack of knowledge, sincerity and professionalism. \\
\hline Abdul Bassioni Bawazeer et al. (2007) & $\begin{array}{l}\text { Site safety inspections by using more qualified safety } \\
\text { supervisors are not done. Safety awareness is not given. }\end{array}$ \\
\hline Hassanein Hanna et al. (2008) & Safety programs are not carried out. \\
\hline Liang Wang et al. (2010) & $\begin{array}{l}\text { Defining responsibility of each party involved in } \\
\text { construction project and strengthening the supervision of } \\
\text { government departments are not done. }\end{array}$ \\
\hline Charehzehi Ahankoob et al. (2012) & $\begin{array}{l}\text { Safety management error, poor training programs, human } \\
\text { element, act of god, outdated procedure and no clear } \\
\text { monitoring policy. }\end{array}$ \\
\hline Oswald Sherrat Smith et al. (2013) & Poor observation. \\
\hline Sunindijo Zou et al. (2013) & $\begin{array}{c}\text { Management team needs to conceptualize the management } \\
\text { of safety. }\end{array}$ \\
\hline Kumar Vishnu et al. (2014) & $\begin{array}{c}\text { Planning, implementing and reviewing, control of work and } \\
\text { manpower is week. }\end{array}$ \\
\hline Subramani Lordsonmillar et al. (2014) & Poor safety record in the construction industry. \\
\hline Nielsen Kent et al. (2014) & Focusing on safety-related interactions is less. \\
\hline Carcano and Franco-Poot et at. (2014) & $\begin{array}{l}\text { Workers' perceptions of safety practices in their habitual } \\
\text { work environment are not studied. }\end{array}$ \\
\hline Khan Suguna Raghunath et al. (2015) & $\begin{array}{l}\text { Safety policy and standards, safety organization, safety } \\
\text { training, inspecting hazardous conditions, personal } \\
\text { protection program, plant and equipment, safety promotion } \\
\text { and management behavior are taken for granted. }\end{array}$ \\
\hline $\begin{array}{l}\text { Promsorn Soponsakulrat Adulyanukosol } \\
\text { Kaiyarit Chinda et al. (2015) }\end{array}$ & $\begin{array}{l}\text { Non-human error aspects like appropriate safety policy, the } \\
\text { environmental and ergonomic issues, such as ventilation, } \\
\text { light, equipment design, and site layout, are not considered. }\end{array}$ \\
\hline $\begin{array}{l}\text { SaatMohd Subramaniam Shamsudin et al. } \\
(2016)\end{array}$ & Performance is not based on multi-level analyses. \\
\hline Yiu Chan et al. (2016) & $\begin{array}{l}\text { Safety managers (safety-in-charge) influence the } \\
\text { performance of SMS or site safety performance. They are } \\
\text { not serious about it. }\end{array}$ \\
\hline Jothsna Jegan et al. (2017) & $\begin{array}{l}\text { Historical, economical, psychological, technical, procedural, } \\
\text { frequency and the environmental issues are not considered. }\end{array}$ \\
\hline Mohammed Shamsul Bakri et al. (2017) & $\begin{array}{l}\text { Policies, objectives, procedures, methods, roles and } \\
\text { functions that aim at controlling hazard and risk in socio- } \\
\text { technical systems are not considered. }\end{array}$ \\
\hline Chen McCabe Hyatt et al. (2017) & $\begin{array}{l}\text { Safety climate may be geographically sensitive, thus it is } \\
\text { necessary to examine. }\end{array}$ \\
\hline
\end{tabular}

\section{CONCLUSION}

From the above literature review we can conclude the following things:

1. There is lack of knowledge about how to use equipments on site and also lack of management.

2. Owners of large projects should more actively participate in construction safety management in each stage of project execution including project design contract selection, contract development, the construction phase, selecting safe contractors, and developing the safety culture on the projects through safety training and safely recognition programs.

3. Employee perceptions, safety behaviors, and environmental or situational features can be accessed through safety climate surveys, peer observations and systems audits/inspections.

4. The construction site should have good and structured safety practices namely safety policy, education and training, site safety inspection, safety auditing, safety meeting, site safety organization, personal protective equipments, emergency support and safety measuring devices, fall protective systems, and safety promotions.

5. Warning signs, guides or reflector should be displaced where necessary on site. 
6. Construction Company should look to improve their policy or the construction design so as to cope with the environmental factors.

7. Behavior based safety management should be proposed to rectify the human ware failures.

8. Project management personnel should contribute to safety climate development by improving their conceptual skill as long as they include safety as one of the important aspects when performing their roles.

9. Continuous safety development should include 6 steps. These steps involve creating safety regulation, identify hazard, assess and evaluate risk, decide precaution, record findings, and updating finding in relation to the work condition.

\section{ACKNOWLEDGEMENT}

The Authors thankfully acknowledge to Dr. C. L. Patel, Chairman, Charutar Vidya Mandal, and Er. V. M. Patel, Hon. Jt. Secretary, Charutar Vidya Mandal, Prof. (Dr.) Indrajit Patel, Principal, B.V.M. Engineering College, Dr. L. B. Zala, Head and Professor, Civil Engineering Department, Prof. J. J. Bhavsar, Associate Professor, Civil Engineering Department, B.V.M. Engineering College, Vallabh Vidyanagar, Gujarat, India for their motivations and infrastructural support to carry out this research.

\section{REFERENCES}

[1] Abdul-Rashid Ibrahim, Bassioni Hesham, Bawazeer Faez (2007), "Factors Affecting Safety Performance in Large Construction Contractors in Egypt", PP: 661-670

[2] Charehzehi Aref, Ahankoob Alireza(2012), "Enhancement of Safety Performance at Construction Site", International Journal of Advances in Engineering \& Technology (IJAET) Volume 5, Issue 1, ISSN: 22311963, PP: 303-312

[3] ChenYuting, McCabeBrenda, Hyatt Douglas(2017), "Impact of individual resilience and safety climate on safety performance and psychological stress of construction workers: A case study of the Ontario construction industry", Journal of Safety Research, PP: 167-176

[4] HassaneinAmr A. G., Hanna Ragaa S. (2008), "Safety Performance in the Egyptian Construction Industry", Journal of Construction Engineering and ManagementPP: 451-456

[5] JainDr. S. K. (2007), "Meeting the Challenges in Industrial Safety Management in Construction Works", PP: $1-9$

[6] Jothsna C., Jegan R. (2017), "Factors Influencing Safety in Construction Project and Behavior Based Safety Management Approach", International Journal for Research in Applied Science \& Engineering Technology (IJRASET) Volume 5, Issue 3,ISSN: 2321-9653, PP: 425-441

[7] Kanchana S., Sivaprakash P., Joseph Sebastian (2015), "Studies on Labour Safety in Construction Sites", Hindawi Publishing Corporation Volume 2015, PP: 1-6

[8] Khan K. Imthathullah, Suguna K.,Raghunath P. N. (2015), “ A Study on Safety Management in Construction Projects", International Journal of Engineering Science and Innovative Technology (IJESIT) Volume 4, Issue 4, ISSN: 2319-5967, PP: 119-118

[9] Khan K. Imthathullah, Suguna K., Raghunath P. N. (2015), "Factor Analysis on Safety Management in Construction Projects”,Asian Journal of Applied Sciences (ISSN: 2321 - 0893) Volume 03 - Issue 04,PP: 766-775

[10] Kumarav. Praveen, Vishnuvardhanck.(2014), "A Study on Construction Jobsite Safety Management", International Journal of Innovative Research in Science, Engineering and Technology (IJIRSET), Volume 3, Special Issue 1, ISSN : $2319-8753$, ISSN : 2347 - 6710, PP: 44-52

[11] Liang Yubao, Wang Xian cheng(2010), "How to Strengthen Safety Management in Construction and Installation Project", (IEEE) PP: 391-395

[12] Mohd. Aqleem Mir, Bibha Mahto (2015), "Site Safety And Planning For Building Construction",International Research Journal of Engineering and Technology (IRJET) Volume 02, Issue 02, e-ISSN: 2395 -0056, p-ISSN: 2395-0072, PP: 650-656

[13] Mohammed Y.D., Shamsul B.M.T., Bakri M.I. (2017), "Assessing Workers Safety Management Knowledge on Construction Site", International Journal of Engineering Research \& Science (IJOER) Volume 3, Issue 5, ISSN: 2395-6992, PP: 20-26

[14] Nielsen Kent J. (2014), "Improving safety culture through the health and safety organization: A case study", Journal of Safety Research 48, PP: 1-17

[15] Oswald David, Sherratt Fred, Smith Simon (2013), "Exploring factors affecting unsafe behaviours in construction", Association of Researchers in Construction Management Volume 2, Issue 4, PP:335-344 
[16] Promsorn Panassaya, Soponsakulrat Parichat, Adulyanukosol Calmin, Kaiyarit Pichapa, Chinda Thanwadee(2015), "Identifying Root Causes of Construction Accidents: Non - Human Error Factors", Int'l Journal of Computing, Communications \& Instrumentation Engg. (IJCCIE)Volume 2, Issue 1,ISSN 2349-1469 EISSN 2349-1477, PP: 1-5

[17] SaatMohd Zaidi Mat, Subramaniam Chandrakantan, Shamsudin Faridahwati Mohd (2016), "Research Issues In Safety Performance: A Literature Review”, e-Academia Journal Volume 5, Issue 2,PP: 143-147

[18] Selvam A, Priyadarshini Krithika, "Safety Management and Hazards Control Measures in Construction", Journal of Mechanical and Civil Engineering (JOSR), e-ISSN: 2278-1684, p-ISSN, PP: 97-101

[19] Sunindijo Riza Yosia, Zou Patrick X. W. (2013), “Conceptualizing Safety Management in Construction Projects", Journal of Construction Engineering and Management (ASCE)CO.1943-7862.0000711, PP: 138

[20] Subramani T, Lordsonmillar R. (2014), "Safety Management Analysis In Construction Industry",Int. Journal of Engineering Research and Applications,ISSN : 2248-9622, Vol. 4, Issue 6( Version 5), PP: 117 120

[21] Yiu Nicole S. N, Chan Daniel W. M. (2016), “A Taxonomic Review of the Application of Safety Managements systemsin Construction”, Journal of International Scientific Publications Volume 10,ISSN 1314-7234, PP:394-408

\section{AUTHORS' BIOGRAPHY}

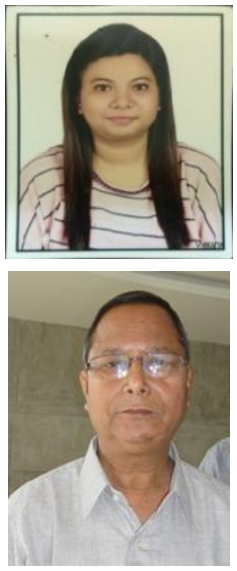

Divya D Patel, received her Bachelor of Technical degree in Civil Engineering from the Dharmsinh Desai University (Nadiad), in 2016. At present, she is a final year student of Master's Technology in Construction Engineering \& Management from Birla Vishvakarma Mahavidyalaya, Gujarat Technological University.

Prof. Jaydevbhai J. Bhavsar, received his Bachelor of Engineering degree in Civil Engineering from the Birla Vishvakarma Mahavidyalaya, Sardar Patel University in 1978. In 1986 he received his Master's Degree in Building Science and Technology from University of Roorkee. He joined Birla Vishvakarma Mahavidyalaya Engineering College as a faculty where he is an Assistant lecturer of Civil Engineering Department with a total experience of 37years in the field of Research, Designing and education. He is guiding M.E./ M.Tech (Construction Engineering \& Management) Thesis work in the field of Civil/ Construction Engineering. He has papers published in National Conferences and International Journals.

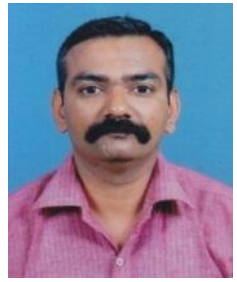

Dr. Jayeshkumar Pitroda, received his Bachelor of Engineering Degree in Civil Engineering from Birla Vishwakarma MahavidyalayaEngineering College, Sardar Patel University in 2000. In 2009 he received his master's degree in Construction Engineering and Management form Birla Vishwakarma Mahavidyalaya Sardar Patel University. In 2015 he received his Doctor of Philosophy (Ph.D.) Degree in Civil Engineering from Sardar Patel University. He joined Birla Vishwakarma Mahavidyalaya Engineering College as a faculty in 2009, where he is Assistant Professor of Civil Engineering Department with a total experience of 17 years in the field of Research, Designing and Education. He is guiding M.E. / M.Tech (Construction Engineering and Management) thesis work in the field of Civil / Construction Engineering. He has published many papers in National / International Conferences and International Journals. He has published seven Research Books in the field of Civil Engineering, Rural Road Construction, National Highways Construction, Utilization of Industrial Waste, Fly Ash Bricks, Construction Engineering and Management, Eco-friendly Construction.

Citation: Dr. Jayeshkumar Pitroda et.al. (2017) A Critical Review on Safety Management in Construction Projects, International Journal of Constructive Research in Civil Engineering, 3(4), pp.148-154. DOI: http://dx.doi. org/10.20431/2454-8693.0304013

Copyright: (C) 2017 Dr. Jayeshkumar Pitroda, This is an open-access article distributed under the terms of the Creative Commons Attribution License, which permits unrestricted use, distribution, and reproduction in any medium, provided the original author and source are credited. 